\title{
Design Research as a Variety of Second Order Cybernetic Practice
}

\author{
Ben Sweeting • University of Brighton, UK・ R.B.Sweeting/at/brighton.ac.uk \\ Constructivist Foundations, Volume 11, Issue 3. http://constructivist.info/11/3
}

\section{Structured Abstract}

\section{Background(s) - Design Theory}

Perspective - Second-order cybernetics

Context - The relationship between design and science has shifted over recent decades. One bridge between the two is that of cybernetics, which offers perspectives on both in terms of their practice. From around 1980 onwards, drawing on ideas from cybernetics, Ranulph Glanville has suggested that rather than apply science to design, it makes more sense to understand science as a form of design activity, reversing the more usual hierarchy between the two. I return to review this argument here, in the context of recent discussions in this journal regarding second order science (SOS).

Problem - Despite numerous connections to practice, second order cybernetics (SOC) has tended to be associated with theory. As a result, SOC is perceived as separate to the more tangible aspects of earlier cybernetics in a way that obscures both the continuity between the two and also current opportunities for developing the field.

Method - I review Ranulph Glanville's understanding of design, and particularly his account of scientific research as a design-like activity, placing this within the context of the shifting relation between science and design during the development of SOC, with reference to the work of Horst Rittel and Paul Feyerabend. Through this, I summarise significant parallels and overlaps between SOC and the contemporary concerns of design research.

Results - I suggest that we can see design research not just as a field influenced by cybernetics, but as a form of SOC practice even where cybernetics is not explicitly referenced.

Implications - Given this, design research offers much to cybernetics as an important example of SOC that is both outward looking and practice based. As such it bridges the gap between SOC and the more tangible legacy of earlier cybernetics, while also suggesting connections to contemporary concerns in this journal with SOS in terms of researching research.

Constructivist content - By suggesting that we see design research as an example of SOC, I develop connections between constructivism and practice.

Key Words - Science, Design Research, Second order cybernetics, Second order science, Practice, Ranulph Glanville 


\section{Introduction}

1. In recent years there has been a resurgence of interest in cybernetics amongst designers. This has been prompted in part by the increased availability and affordability of technologies with which to augment the environments we design, and those we design in, which has fuelled interest in ideas regarding interactivity. While this technological focus is an important aspect of what cybernetics offers design, the relations between the two fields run much deeper. These connections have been explored explicitly in the work of Ranulph Glanville (1999, 2006a, 2006b, 2007a, 2007b, 2007c, 2009a, 2010, 2011a, 2014b) whose work I use as a point of departure in this paper. ${ }^{1}$

2. Drawing on Pask's (1976) Conversation Theory and the common characterisation of design in terms of conversation (such as by Schön 1991), Glanville (2007c, 2009c) has suggested a close analogy between cybernetics and design, understanding both as "essentially constructivist" activities (Glanville 2006a: 63; 2013). The parallels Glanville draws are significant enough for him to claim that "cybernetics is the theory of design and design is the action of cybernetics" (Glanville 2007c: 1178).

3. While part of Glanville's motivation in developing the connection between cybernetics and design has been the insight that the former might bring to the latter, it is an important aspect of his position that the converse is also the case: that design can set an example to cybernetics in terms of practice and so inform it, not just vice versa. Thus the relationship between cybernetics and design is to be understood as one of mutual overlap and support and, as such, one which avoids the difficulties that can follow from the application to design of theories external to it (a problem which seems to recur in architecture in particular) and the more general shortcomings that can follow from our tendency to see the relation of theory and practice as predominantly the application of the former to the latter (Glanville 2004a, 2014a, 2015; see also Sweeting 2015c).

4. More specifically, Glanville's understanding of design as being the action of cybernetics is part of his characterisation of second order cybernetics (SOC) as being concerned with how cybernetics is to be practiced rather than, as can tend to be the case, a theoretical reflection on this (Glanville 2011b; Sweeting 2015b). This concern was particularly evident during his time as President of the American Society for Cybernetics (ASC) during which he often referred to Margaret Mead's (1968) challenge, delivered in her address to the inaugural ASC conference, to practice cybernetics in line with its own ideas. While the principal legacy of Mead's remarks has been the epistemological concerns of SOC, as developed by Heinz von Foerster (1995,

\footnotetext{
${ }^{1}$ Together with Neil Spiller, Ranulph supervised my PhD research and although this article has been developed after his passing, it is significantly influenced by my conversations with him. In addition to his work, on the relationship between cybernetics and design see also: Dubberly and Pangaro (2007, 2015); Fischer (2015); Fischer and Richards (in press); Furtado Cardoso Lopes (2008, 2009a, 2009b); Gage (2006, 2007a, 2007b); Goodbun (2011); Herr (2015); Jonas (2007a, 2007b, 2012, 2014, 2015a, 2015b); P. Jones (2014); Krippendorff (2007); Krueger (2007); Lautenschlaeger and Pratschke (2011); Lobsinger (2000); Mathews (2005, 2006, 2007); Pratschke (2007); Ramsgard Thomsen (2007); Rawes (2007); Spiller (2002); Sweeting $(2014,2015 \mathrm{c})$.
} 
2003a) and others, their original context is that of the practice of the society itself. It is this aspect to which the ASC returned during Glanville's presidency, in terms of both the form and content of its conferences, which explored cybernetics' relation to practice using conversational, cybernetic, formats (Baron, Glanville, Griffiths, \& Sweeting 2015; Glanville 2011b, 2012; Glanville, Griffiths, \& Baron 2014; Glanville \& Sweeting 2011; van Ditmar \& Glanville 2013). ${ }^{2}$

5. In contrast to this understanding of its relation to practice, Andrew Pickering (2010: 25-26) has characterised SOC as a turn away from the more tangible modes of experimentation that characterised earlier phases of cybernetics, and towards the linguistic. This view can be countered: SOC is a reflection on the performative involvement of observers within their observations in contrast to the separation of observer and observed in conventional science. This is very much in line with Pickering's own emphasis, for example in his comments on R.D. Laing's psychiatry as taking seriously "the idea that we are all adaptive systems, psychiatrists and schizophrenics alike" (Pickering 2010: 8) or his reference to Pask's account of the "participant observer" who tries to maximise interaction with what he or she observes in order to explore it (343-4).

6. However, even its advocates must admit that SOC can run the risk of becoming overly introverted, especially given its central concern with self-reference. Recent thinking regarding von Foerster's development of SOC has addressed this concern by understanding it as the beginnings of a research programme rather than as primarily a form of worldview, and as prompting the "new course of action" suggested in this journal under the heading of "second-order science" (SOS) (A. Müller \& Müller 2007; K. H. Müller 2008, 2011; Riegler \& Müller 2014). ${ }^{3}$ In this light I suggest that Glanville's understanding of design, and particularly his $(1999,2014 \mathrm{~b})$ account of the relation between design and science which I discuss below, allows us to view the currently expanding field of design research as a contemporary variety of SOC practice, whether SOC is explicitly invoked or not. ${ }^{4} \mathrm{My}$ purpose in doing so here is not primarily to add to what SOC can bring to design research, which has been explored in depth elsewhere by many others. Rather, my focus is on what design can bring to cybernetics, in line with what I have understood as being part of Glanville's own motivations for developing this analogy, as noted above. Design research offers an example of how SOC can develop as a practice-based and outward looking enquiry, while also suggesting a way of integrating the legacy of tangible experimentation from earlier cybernetics with its contemporary concerns.

\footnotetext{
${ }^{2}$ See also the recent special issue of this journal on alternative conference formats which was inspired in part by these ASC conferences (Hohl \& Sweeting 2015; regarding the ASC conferences, see especially: Richards 2015; Sweeting \& Hohl 2015).

${ }^{3}$ See also http://www.secondorderscience.org/

${ }^{4}$ Given that cybernetics stresses the interdependency between acting and understanding, and so between theory and practice (see e.g. Glanville 2014a; Sweeting 2015c), I could equally refer to design research as a contemporary variety of second order cybernetics as to one of second order cybernetic practice. Nevertheless I feel it is important to stress the practical here, given that SOC, and constructivism generally, currently risk being seen more as a worldview than an active research tradition.
} 


\section{Method and Practice in Design and Research}

7. During the period of scientific and technological optimism that followed the Second World War, there was a tendency, as evident in what is usually referred to as the design methods movement, to see design as something that should be put on rational scientific foundations. ${ }^{5}$ Since around 1980 this view has been countered by arguments that have seen design as a discipline in its own right and so as being of the same status as science rather than something to be corrected by it. Amongst these, the account which Glanville (2014b) presented at the 1980 Design: Science: Method conference, later expanded as the journal article Researching Design and Designing Research (1999), is particularly strongly framed, reversing what had been the more usual hierarchy. Rather than seeing design research as one specific form of scientific research, Glanville argues that, instead, we can see science as a specific form of design enquiry. This follows from the way that scientific research inevitably involves design activity, for instance in devising and setting up experiments, but not vice versa. ${ }^{6}$ Design is, it follows, the more general case and, therefore, "it is inappropriate to require design to be "scientific": for scientific research is a subset (a restricted form) of design, and we do not generally require the set of a subset to act as the sub subset to that subset any more than we require [that] the basement of [a] building is its attic" (Glanville 1999: 87-88).

8. This argument and others like it around that time, such as those put forward by Bruce Archer (1979), Nigel Cross (1982) and Donald Schön (1991), consolidate a shift during the 1970s from trying to base design on the scientific method to the idea that it has its own epistemological foundations, independent of science (for an overview of this shift, see Cross 2007). The attempt to order design according to a linear version of the scientific method, understood as moving from analysing the problem at hand to testing and optimising solutions to it, failed for reasons that seem obvious in retrospect: because design involves the creation of new situations, design questions cannot be fully formulated in advance but shift and change as they are explored and as proposals are enacted. One of the most important accounts of these limitations is that developed by design theorist Horst Rittel, who, writing with the urban designer Melvin Webber, characterised the situations which designers encounter as "wicked problems", the complex interdependencies of which make them unsolvable using conventional linear problem solving (Rittel 1972; Rittel \& Webber 1973, 1984).

9. On the face of it, Rittel and Webber's observations mark an incompatibility between design and science in terms of method. Indeed the exhaustion of the design methods movement by the 1970s - with leading figures such as Christopher Alexander (1984), John Christopher Jones (1984) and, indeed, Rittel distancing themselves from it - along with the unravelling of modernism more generally during that decade, marks something of a parting of the ways between design and science (architecture, for instance, would increasingly turn towards history and philosophy, rather than science,

\footnotetext{
${ }^{5}$ See for instance: Alexander (1964); Broadbent and Ward (1969); Simon (1996). For a critical discussion of the design methods movement, see Gedenryd (1998).

${ }^{6}$ This is not to say that designers do not make use of scientific research but that doing so is not essential to what design is, whereas design is a core aspect of research and so science.
} 
for theoretical support). However, given Glanville's SOC inspired argument noted above, this separation between design and science is not what we might expect. If science is a limited form of design, then is it not the case that scientific approaches should be commensurable with design, even if not a basis for it? This apparent disjunction is only the case if we follow the changes in how design was thought about during this period without also following the comparable changes regarding science.

10. Design research and the philosophy of science broadly parallel each other over this period. Both move from a concern with method in the 1960s through a critique of this in the 1970s to new foundations from the 1980s onwards, focusing on what designers and scientists actually do in practice rather than on what seems ideal in theory. As noted above, this led to design being seen as a discipline in its own right (Archer 1979), with its own "designerly ways of knowing" (Cross, 1982) and a refocusing from methodology to broader and more practice based concerns, under the heading of design research (for an overview, see for instance: Grand \& Jonas 2012; Michel 2007; Rogers $\&$ Yee 2015). In the context of science there was a comparable turn during the 1970 s and 1980s towards understanding it in terms of the social and material agency of research as practiced, with the growth of the fields of the Sociology of Scientific Knowledge (SSK) and Science and Technology Studies (STS), such as in the work of Karin Knorr Cetina, David Gooding, Bruno Latour and Pickering amongst others (for an overview see Pickering 1992). These accounts are suggestive of a more designerly paradigm in science in line with Glanville's argument. Indeed, accounts of experimentation in SSK/ STS can be read almost as if describing the activities of a design studio; see for instance: Gooding (1992), Pickering $(1993,1995)$ and Knorr Cetina (1992), who even uses a direct analogy with architecture.

11. In this light, what appears to be a rupture between design and science during the 1970 s is instead a close parallel. Indeed, key critiques advanced in each area - that of Rittel in design, and that of Paul Feyerabend $(1970,1982,1993)$ in science - have similar content. Rittel and Feyerabend were colleagues at UC Berkeley while they were developing their ideas. Both were influenced by thinking in cybernetics and systems at that time - Rittel particularly by Ross Ashby (Fischer \& Richards in press), while Feyerabend (1982: 64) refers to "new developments in systems theory", which was flourishing at Berkeley (which was also home to C. West Churchman) and elsewhere in California at the time (where Gregory Bateson amongst others was based), and his (1982: 18) comments regarding participant observers reflect contemporaneous preoccupations of SOC.

12. Science, like design, involves creating new ideas and understanding; and, therefore, as in design, the criteria and methods appropriate will change as part of the process and cannot be defined in advance if science is to progress:

\footnotetext{
...to ask how one will judge and choose in as yet unknown surroundings makes as much sense as to ask what measuring instruments one will use on an as yet unknown planet. Standards which are intellectual instruments often have to be invented, to make sense of new historical situations just as measuring instruments have constantly to be invented to make sense of new physical situations. (Feyerabend 1982: 29)
} 
13. Feyerabend's $(1970,1993)$ reductio ad absurdum argument against the predefined methods that were characteristic of the philosophy of science at the time, concludes by showing that the only criteria that can be given in advance, that will not inhibit scientific progress, is that "anything goes". This also appears in Rittel and Webber (1973: 164), while Rittel (1972: 393) has "everything goes": because designers inevitably encounter new and ambiguously defined situations (it being the purpose of design to create the new), they have no well-defined problems to solve or enumerable lists of options to pick from and "any new idea for a planning measure may become a serious candidate" (Rittel \& Webber 1973: 164). This phrase is also anticipated by theatre director Joan Littlewood (1964: 432) in describing the Fun Palace project, on which cybernetician Gordon Pask was a key collaborator along with architect Cedric Price (see e.g. Lobsinger 2000; Mathews 2005, 2006, 2007; Spiller 2006: 48-50), and which is equally concerned with the in principle unpredictable. Furthermore, Feyerabend's (1982: 202) comment that the proponents of scientific theory are out of touch with scientific practice echoes the situation in design, where design methods had become an academic game divorced from practice, as both Alexander (1984: 309) and Jones (1984: 26) point out. ${ }^{7}$

14. While Archer (1979) differentiated design as a third disciplinary pole with the same status as the traditional "two cultures" of the arts and sciences (Snow 1961), Glanville (2014b) argues against this separation and, instead, characterises all research as being a design-like activity. This designerly continuity across different fields is, however, obscured by popular misrepresentation of science as a logical and predictable activity, such as are perpetuated in the structure of traditional scientific papers, which Peter Medawar (1996) has critiqued as a fraudulent account of what scientists actually do in practice. Glanville (2014b: 111) calls for honesty about how research is practiced in all disciplines, and suggests that this will make similarities clear between apparently quite different fields. In this, Glanville reflects a willingness to transcend disciplinary boundaries that is characteristic of cybernetics' origins, which had cut across distinctions between research fields as well as those between objectivity and subjectivity, human and machine, and mind and body.

15. In stressing the continuities between design and other disciplines, Glanville (2014b) contrasts his account with that of Archer (1979), whose positioning of design in terms of its own disciplinary pole, separate to the arts and the sciences, risks isolating it from other research traditions. Glanville's understanding, however, still gives design research the special status of Archer's account: given the parallels he draws between design and research, Glanville recognises design research as a self-reflexive activity of

\footnotetext{
${ }^{7}$ As one of the anonymous reviewers of this article suggests, the shift away from science in design can be thought about in terms of a search for forms of rigour that makes sense in a design context, such as for example those described by Schön (1988). Feyerabend's $(1982,1993)$ argument, however, indicates that the scientific method as it had been promoted was unsatisfactory not just in making sense of design but also in accounting for scientific practice itself (Feyerabend demonstrates that examples commonly regarded as paradigmatic by the advocates of method violate the methodological principles they propose). That is, in this period, the need for an understanding of rigour that makes sense in the context of practice is a feature not just of design but also science. Thanks to the anonymous reviewer for prompting my thoughts on this point.
} 
researching research (Glanville 2014b: 116-119). That is, as design is a core part of research activity, to research design is to inquire into an aspect of research activity itself. In so doing, Glanville anticipates recent discussions in this journal regarding second order science (SOS) as research activity focused on research itself (Müller \& Riegler 2014a, 2014b; Riegler \& Müller 2014). I return to this below.

\section{Design Research and Second Order Cybernetics}

16. SOC was developed in the context of the shifts in understanding science and design that I have summarised above, and parallels these concerns. As such SOC sits in a pivotal position within cybernetics' wider history. In consolidating its epistemology and, with it, an ability to rigorously address the issues of self-reference towards which a field concerned with circularity is inevitably drawn, it is with SOC that cybernetics reaches maturity as a discipline. That this happens simultaneously with the fragmentation of the field during the 1970s, under pressure from changes in external funding climate and professional accreditation (Umpleby 2003; Umpleby \& Dent 1999), has consequences not just for the ideas of SOC but also for how we understand earlier, and other, aspects of cybernetics.

17. Firstly, as the earlier work occurred before the maturity of the field, it is inevitable that it contains inconsistencies in epistemology, approach and terminology. This is further complicated by the way that the fragmentation of the field is often associated with the emergence of critiques of science and technology during the 1970s, of which SOC is one instance. SOC has often, for this reason, been presented in contrast to cybernetics of the first order. The "first" and "second" should not, however, be understood as implying a sequence or the surpassing of one by the other. ${ }^{8}$ Rather, SOC is specifically the application of cybernetics to itself- "the cybernetics of cybernetics" as von Foerster titled Mead's (1968) paper (von Foerster 2003b: 302). ${ }^{9}$

18. The terminology of "first" and "second" can obscure the continuity between SOC and earlier cybernetics. While Glanville has spent considerable effort in distinguishing the two (e.g. Glanville 1997, 2004b), he has also recognised that cybernetics always involves second order considerations and did so even at its origins (Glanville 2013: 28) and that "it would be better, nowadays, to talk only of Cybernetics, without orders: thus bringing the different approaches into proximity" (Glanville 2002). This is certainly the case for Mead and Bateson, whose backgrounds in anthropology involved a consideration of the participation of observers in what they observe (see e.g. their discussion in Brand, Bateson, \& Mead 1976), and for Ashby in his (1991)

\footnotetext{
${ }^{8}$ While Fischer and Richards (in press), rightly point out considerable overlaps between the development of SOC and Rittel's characterisation of first- and second-generation design methods, it should be remembered that "first" and "second" are used in different ways in each context.

${ }^{9}$ This development was both necessary for the field to consolidate its own disciplinary foundations, and has also made possible innovatively reflexive research programmes that are of particular interest in exploring those questions regarding cognition, society, epistemology and ethics which inevitably involve self-reference. For a fuller discussion of SOC see e.g.: Glanville (1997, 2002, 2004b, 2011b, 2013); A. Müller and Müller (2007); K. H. Müller (2008, 2011); Scott (2003, 2004, 2011); von Foerster (1995, 2003b); von Foerster and Poerksen (2002).
} 
understanding of the black box system as involving the observer as part of it. Even Norbert Wiener, according to Pask (as reported by Glanville 2002; 2013: 33), recognised that there were further steps to take in developing the subject. Indeed, Alvin Toffler's (1970) Future Shock, a book that is emblematic of the criticisms of science and technology that are often assumed to also apply to cybernetics (e.g. Lobsinger 2000: 134), is anticipated two decades earlier in the similar, cautionary account of technological change in Wiener's (1950) Human Use of Human Beings. In addition, while Pickering (2010) sees SOC as being in contrast to the tangible modes of exploration of the earlier cybernetics in which he is interested, the performative quality of the devices through which Pask, Ashby, Grey Walter and others explored their ideas is an example of the participation of observers in observation on which SOC reflects and places values.

19. Secondly, it is difficult to judge the consequences of SOC for practice as the field within which these implications would have been explored had broken up by the time the possibility of doing so had emerged. The tendency of SOC to be largely theoretical in orientation - which leads Pickering (2010: 25-26) to view it as a form of linguistic turn - needs to be understood in this context of a lack of opportunity for experimental work.

20. With the break up of cybernetics, many of its ideas were absorbed back into its constituent fields. Some research in other disciplines, such as for instance robotics or complexity, can be recognised as a continuation of its ideas and research programme, including its performative approach to experimentation (see, for instance, Pickering's discussion of Rodney Brooks, Stephen Wolfram and Stuart Kauffman; 2010: 60-64, 156-170). Given its continuities with cybernetics, as introduced in part above and discussed further below, the field of design research can be thought of, similarly, as one such successor field. ${ }^{10}$

21. There is a longstanding history of connection and influence between cybernetics and design, as has been summarised by Hugh Dubberly and Paul Pangaro (2015). In particular, Ashby and Pask both engaged directly with design. ${ }^{11}$ Ashby lectured at the Ulm School of Design with Rittel (see Fischer \& Richards in press) and was also a significant influence on Alexander. ${ }^{12}$ Pask, meanwhile, became increasingly involved in architecture from the 1960s onwards. He was a significant contributor to the prominent Fun Palace project with Price and Littlewood, and collaborated with Nicholas Negroponte at MIT, for whose Soft Architecture Machines (Negroponte 1975) he contributed a chapter. In addition he held a consultant position at the Architectural

\footnotetext{
${ }^{10}$ By "successor field" I do not mean to imply any sense of superiority, but rather the inheritance of ideas.

${ }^{11}$ Other figures could also be mentioned. Dubberly and Pangaro (2015) and K. H. Müller and Müller (2011) also stress the interest of Heinz von Foerster in design. He addressed design audiences (e.g. von Foerster 1962) and was connected to figures such as architect Lebbeus Woods and Stuart Brand, who can be mentioned in his own terms as a cross over figure. Fischer (2015) has suggested connections between Wiener and recent work in design, while the work of Bateson, who was also close to Brand and introduced him and von Foerster, is a point of reference for contemporary discussions of architecture and ecology (see e.g. Goodbun 2011; Rawes 2013).

${ }^{12}$ Although, as Upitis (2013: 504-505) notes, Alexander's (1964) use of Ashby's ideas can be questioned.
} 
Association in London, wrote explicitly on architecture and design (Pask 1963, 1969) and influenced the development of interactive architecture through Negroponte and others such as John and Julia Frazer (Frazer 1993, 1995; Furtado Cardoso Lopes 2008, 2009a; Spiller 2006: 204-210). More recently, figures such as Pangaro, Glanville and Klaus Krippendorff, influenced particularly by Ashby (Krippendorff) or Pask (Glanville, Pangaro), have made prominent contributions in both design research and cybernetics while many others have worked in one field in a way informed by thought in the other.

22. As well as this continuity of people, there is a significant continuity of ideas and approach such that cybernetics can be thought of as design's "secret partner in research" (Glanville 1999: 90-91). While this is not the place for a full discussion of these parallels - I defer here to the accounts of Glanville and the others who I have citedkey points include the following:

- There is a conversational, and so cybernetic, structure that is central to what is distinctive about the way designers work (see for instance Schön's (1991: 76) characterisation of design in terms of a "reflective conversation with the situation"). Glanville has developed this parallel to the extent that, as I have noted, he claims that "cybernetics is the theory of design and design is the action of cybernetics" (2007c: 1178) while it is also what lies behind his $(1999,2014 b)$ characterisation of research in terms of design, as discussed above.

- Both design and cybernetics are concerned with the new, as supported by the tendency of conversation to involve invention at every turn. Both are "essentially constructivist" activities (Glanville 2006a: 63; see also: Glanville 2006b; 2013; Herr 2015) which enable a form of "forward-looking search", as Pickering (2010: 18) has described cybernetics, developing new ideas and possibilities rather than looking to correspond to, or replicate, the real or the optimal.

- The way that designers use drawings and models for exploring ideas rather than as representations of them (Glanville 2009b) resonates closely with the performative nature of the work of Pask and others, who played out their ideas using physical, experimental devices in much the same way (as emphasised in Pickering's (2010) account). In contemporary practice based design research, some work has strong continuity with the sorts of devices made in earlier cybernetics (e.g. that of Mette Ramsgard Thomsen (2007), Jennifer Kanary Nikolov(a) ${ }^{13}$ or Ruairi Glynn ${ }^{14}$ ), but even the use of more analogue media (such as the sorts of pen drawings with which I work; see Sweeting 2014) has a similar attitude to modelling as part of thinking rather than as a representation of thought.

\footnotetext{
${ }^{13} \mathrm{http} / / /$ www.labyrinthpsychotica.org/Labyrinth_Psychotica/Home.html

${ }^{14} \mathrm{http}: / / \mathrm{www}$. ruairiglynn.co.uk/
} 
- Design research is often concerned with epistemological questions regarding the interrelations of designers, other stakeholders, working methods and the knowledge embedded in what is designed. This has often been articulated in terms of differences between research about/into, through/by and for design, following Frayling (1993) and others, and as reviewed and synthesised by Jonas (2012, 2015a, 2015b). These distinctions distinguish between that research which looks at design from the outside or which is applied to it, from that which is conducted as an integral part of it. This resonates strongly with SOC concerns regarding the participation of observers in their observations, and the active difference made by how this participation is configured. Jonas (2007b, 2012, $2015 \mathrm{~b}$ ) in particular has explicitly used the framework of cybernetics, drawing on Glanville (1997), to clarify these points. I return to this below.

- Design is a self-reflexive activity in much the same way as cybernetics, both involving circular reflective processes and being examples of disciplines that can be applied to themselves, in the design of design or the cybernetics of cybernetics.

23. While design research and cybernetics mostly differ in their subject matter, the above parallels are significant. They share both ways of working - a conversational forward-looking search and an interactive, non-representational use of modelling - and also core concerns with observer positions and self-reflexivity in the constitution of their research processes. These parallels hold to the extent that, while design research continues to make reference to cybernetic ideas (for instance in exploring the possibilities of new technologies (e.g. Ramsgard Thomsen 2007; Spiller 2002), or in understanding the relationship between research and design (e.g. Jonas 2007b, 2012, 2014, 2015a, 2015b)), I suggest we can also understand it as a contemporary variety of cybernetic research, whether the connections with cybernetics are made explicitly or not. Seeing design research as an example of SOC in this way, suggests a continuity between the epistemological focus of SOC and the tangible experimentation of earlier cybernetics, a connection which can easily become obscured, as is evident in Pickering's (2010) account.

\section{Second Order Science}

24. As well as helping integrate the more practice-oriented legacy of early cybernetics with SOC, design research can also provide an important point of reference for contemporary discussions of SOS, which have been a recent focus of this journal (and which have led to the present special issue). Karl Müller and Alexander Riegler (2014a) proposed SOS as "a new course of action" in order to reinvigorate SOC - and constructivist approaches generally - as an active research field. They characterise SOS as a reflexive form of research, either in methodological terms through the inclusion of observers as participants (a direct continuation of von Foerster's $(1995,2003$ a) SOC as the "cybernetics of observing systems"), or through self-reflexive domains of research, in the sense of the science of science or, similarly, the cybernetics of cybernetics or the sociology of sociology, such as through meta-analyses of the products or practices of other scientific enquiry. 
25. Müller and Riegler position SOS as a specific research agenda within the significant transformations currently underway in the landscape of science $(\mathrm{K}$. H. Müller 2008, 2011; Müller \& Riegler 2014b). These have partly been, as noted above, in terms of how science has come to be understood in terms of its practice by fields such as SSK and STS, but also through significant changes in this practice itself. This has included: a change of focus away from a mechanistic and reductionist paradigm (associated with Newton and Descartes) towards one based in complexity, adaptation and evolution, which Rogers Hollingsworth and Müller (2008) have labelled in terms of a transition from Science I to Science II; significant changes in the organisational structure of knowledge production, with an increased emphasis on its social robustness and the context of application, which has been labelled as a shift from Mode 1 to Mode 2 (see Nowotny, Scott, \& Gibbons 2006); and growing interest in transformative and transdisciplinary aspects of research (e.g. Nicolescu 2012; Schneidewind \& Augenstein 2012).

26. These various changes in science have all had the effect of science moving towards a more designerly paradigm, in line with Glanville's (2014b) argument discussed above (as noted by Jonas 2014, 2015a). Given this convergence and the historical and conceptual connections that I reviewed above, there is reason to consider SOS as a potential point of interchange between design and science. This is especially so given that there is a considerable overlap between core interests of design research and the two "motivations" for SOS that Müller and Riegler (2014a: 2-3) have put forward: selfreflexivity, and the inclusion of observers.

27. Firstly, self-reflexivity is important in design research in various ways. In a general sense, designers often do this implicitly as they work, reflectively redesigning their design processes to suit the specifics of the situations they encounter. More explicitly, design is a field that, like cybernetics, can be applied to itself in the sense of the design of design. This includes such instances as: the design of particular design methods (e.g. Alexander 1964) or of technologies with which to design (e.g. Frazer 1995; Negroponte 1975; or contemporary developments such as BIM); the way that a design research conference is something that itself needs to be designed (Durrant, Vines, Wallace, \& Yee 2015; Sweeting \& Hohl 2015); and the way that the products of design can allow for a continuation of the design process in them, such as in the architecture of Price (as Price himself remarks; Obrist \& Price 2003: 136).

28. Specific design projects can also explore aspects of design itself, as for instance in Peter Downton's (2004) practice based reflections on epistemology, or the work of Peter Eisenman (Bédard 1994). Indeed, Eisenman's Cannereggio project, for instance, can be considered a meta-analysis in Müller and Riegler's (2014b) sense, for the way it takes Le Corbusier's unbuilt Venice Hospital scheme for the same site as its starting point.

29. Most significantly for SOS, understanding design as a core part of research, as per Glanville's (2014b) account discussed above, positions design research as a field of researching research. This observation holds possibilities yet to be fully explored, offering design research a field of application in science rather than vice versa, as is more often the case. 
30. Secondly, as noted above, the position of the observer has been a theme of particular importance in design research as part of the field's shift from its mostly professional origins to being seen in more academic terms. This has included careful delineations between ways in which designers and others observe and participate in design, and of the ways in which material artefacts operate variously as part of the research process, as the object of enquiry, as output or dissemination and sometimes as more than one of these depending on their context. At noted above, one important and widespread way in which these distinctions have been made is by distinguishing in terms of research about/into, for, and through/by design. As Jonas (2012: 34) discusses, the value of this sort of categorisation is that it differentiates on the basis of the attitudes and intentions of designers, rather than in terms of subject matter (which would not make sense in design because of its tendency towards diverse and ambiguously delineated content). This has helped clarify where design is used actively as a research process to explore a topic (through/by), where separate research is applied in design, such as in research and development or market research (for), and where design is the object of separate study by another discipline, such as history or sociology (about/into). In elaborating on and clarifying these distinctions, which were initially rather ambiguous, Jonas has drawn on Glanville's (1997) description of different observer positions and orientations as a foundation, associating research through with the engaged SOC observer, and for and about with the detached observer of first order cybernetics (FOC). Jonas distinguishes a new category of research as design to correspond to where, in Glanville's scheme, the observer is inside the inquiring system and looking inwards, and interprets this in terms of "design as the inaccessible medium of knowledge production" and the role of abductive reasoning (Jonas 2015b: 35). ${ }^{15}$

31. Categorisations of this sort are very much in the spirit of SOC and are highly relevant for SOS; and we can think of research for, about/into, through/by and as in this context in much the same way as in design. It is the observer-included modes of research through/by and as that are of most relevance (these being associated with SOC). Examples include Glanville's approach to conference design in terms of using cybernetic processes, and so acting out the content of the conference in its form (Glanville 2011b; Sweeting \& Hohl 2015); and the performative aspects of the devices of Pask and others, as stressed by Pickering (2010). The more detached modes of research about/into or for also have their counterparts, and would include historical and theoretical work, including this present article and also accounts such as that of Pickering and others to which I have referred. ${ }^{16}$

\footnotetext{
${ }^{15}$ Given Glanville's (1997) enigmatic silence regarding this category, it makes sense to associate it with the role of tacit knowledge in design, especially when seen in the context of Jonas' (2015a, 2015b) presentation of these categories in terms of their relations with each other. Locating the tacit here can help clarify the relation between the research involved in any design act, and research through design, which is in need of more explicit articulation, even if this could still be through various media or embedded in artefacts.

${ }^{16}$ Note that to write about SOC is a first order activity. This is why neither von Foerster (2003b: 301) nor Glanville (2002) see the need for any third or fourth orders of cybernetics; these would simply be instances of its first or second orders.
} 
32. While Jonas has used the terminology of FOC and SOC to give a foundation to these designerly categories, in turn they offer complementary possibilities back to cybernetics. Whereas the phrasing of FOC and SOC invites a sharp distinction in terms of whether the observer is included or not, and can be confusingly interpreted in terms of a chronological sequence as discussed above, the categories of for, about/into, through/by and as distinguish something of the nature of an observer's involvement, not just the acknowledgement of it, and invites these different observer positions to be seen in productive combination. This latter point is important for SOS, especially where it is conceived in terms of reflexive operations such as meta-analyses, as it requires a close relationship to the more conventional first order science on which it is to operate (Müller \& Riegler 2014b).

33. Given these significant overlaps, design research is a productive point of comparison for SOS. In particular, it suggests a possible example for how SOS can be constituted as a research field that is practice based and outward looking, both aspects that are important in this "new course of action" (Müller \& Riegler 2014a). This is partly through the connections between SOC and earlier, more tangible, forms of cybernetics that are suggested by design research, and also through examples of research through design, which is notable for the way that even some of its most abstracted and introverted moments retain rich potential for concrete connections with the world.

\section{Conclusion}

34. In this paper I have drawn on the continuities, both of concepts and participants, between SOC and the field of design research, in order to position SOC in terms of practice rather than as a mainly theoretical perspective. I have drawn, in particular, on Glanville's (2014b) account of scientific research as a form of design activity, understanding this in the context of the shifting relationship between design and science during the formative period of both SOC and design research, and since.

35. I have suggested that design research is not just a field that is influenced by SOC but a contemporary variety of it, whether this connection is made explicitly or not, in a similar way that other fields can be regarded as continuing or reinventing cybernetic concerns. Understanding design research in this way suggests a continuity between the epistemological concerns of SOC and the material experimentations of earlier cybernetics, in contrast to the way that SOC is sometimes regarded as a turn away from these more tangible qualities.

36. These connections with cybernetics' past are also relevant to contemporary discussions of SOS. Given that design research shares the central concerns of SOS with both self-reflexivity and the inclusions of observers as active participants, it is suggestive of ways in which SOS may develop as a field of research. 


\section{Acknowledgements}

This article was developed from a presentation given at the 2015 conference of the International Society for Systems Science in Berlin (Sweeting 2015a) in a session chaired by Peter Jones, whom I thank for his comments and encouragement. Thanks also to the American Society for Cybernetics, who funded my attendance at that conference as part of the 2014 Heinz von Foerster Award. The ideas presented here have been influenced by discussions with Nick Beech, Murray Fraser, Tim Ivison and Simon Sadler at the Canadian Centre for Architecture in Montreal as part of an ongoing collaborative research project funded by the Andrew W. Mellon Foundation. ${ }^{17}$ Thanks also to Tanya Southcott, Tilo Amhoff, Stuart Umpleby, the editors and the anonymous reviewers for their comments and assistance.

\section{Reference List}

Alexander, C. (1964). Notes on the synthesis of form. Cambridge, MA: Harvard University Press.

Alexander, C. (1984). The state of the art in design methods. In N. Cross (Ed.), Developments in Design Methodology (pp. 309-316). Chichester: Wiley. (Reprinted from: DMG newsletter, 5(3), 3-7, 1971.).

Archer, B. (1979). Design as a discipline. Design Studies, 1(1), 17-20. Available at: http://www.dx.doi.org/10.1016/0142-694X(79)90023-1

Ashby, W. R. (1991). General systems theory as a new discipline. In G. J. Klir (Ed.), Facets of systems science (pp. 249-257). New york, NY: Plenum Press. (Reprinted from: General Systems Yearbook, 3(1), 1-6, 1958).

Baron, P., Glanville, R., Griffiths, D., \& Sweeting, B. (Eds.). (2015). Living in Cybernetics: Papers from the 50th Anniversary Conference of the American Society for Cybernetics. Special double issue of Kybernetes, 44(8/9). Retrieved from http://www.emeraldinsight.com/toc/k/44/8\%2F9

Bédard, J.-F. (Ed.). (1994). Cities of artificial excavation: the work of Peter Eisenman, 1978-1988. New York: Rizzoli International.

Brand, S., Bateson, G., \& Mead, M. (1976). For God's Sake, Margaret: Conversation with Gregory Bateson and Margaret Mead. CoEvolutionary Quarterly, 10, 3244. Retrieved from http://www.oikos.org/forgod.htm

Broadbent, G., \& Ward, A. (1969). Design methods in architecture. London: Lund Humphries.

Cross, N. (1982). Designerly ways of knowing. Design Studies, 3(4), 221-227. Available at: http://www.dx.doi.org/10.1016/0142-694X(82)90040-0

Cross, N. (2007). From a design science to a design discipline: Understanding designerly ways of knowing and thinking. In R. Michel (Ed.), Design research now: Essays and selected projects. Basel: Birkhäuser.

Downton, P. (2004). Studies in Design Research: Ten Epistemological Pavilions. Melbourne: RMIT University Press.

Dubberly, H., \& Pangaro, P. (2007). Cybernetics and service-craft: Language for behavior-focused design. Kybernetes, 36(9/10), 1301-1317. Available at: http://www.dx.doi.org/10.1108/03684920710827319

\footnotetext{
${ }^{17}$ See http://www.cca.qc.ca/en/study-centre/2307-19451975-british-culture-for-architecture
} 
Dubberly, H., \& Pangaro, P. (2015). How cybernetics connects computing, counterculture, and design. In Hippie Modernism: The Struggle for Utopia. Minneapolis, MN: Walker Art Center. Retrieved from http://www.dubberly.com/articles/cybernetics-and-counterculture.html

Durrant, A. C., Vines, J., Wallace, J., \& Yee, J. (2015). Developing a Dialogical Platform for Disseminating Research through Design. Constructivist Foundations, 11(1), 401-434. Retrieved from http://www.univie.ac.at/constructivism/journal/11/1/008.durrant

Feyerabend, P. K. (1970). Against Method. In M. Radner \& S. Winokur (Eds.), Analyses of Theories and Methods of Physics and Psychology, Vol. IV (pp. 17130). Minneapolis: University of Minnesota Press. Retrieved from http://www.mcps.umn.edu/philosophy/completeVol4.html

Feyerabend, P. K. (1982). Science in a Free Society. London: Verso. (Original work published: 1978).

Feyerabend, P. K. (1993). Against Method (3rd ed.). London: Verso. (Original work published: 1975).

Fischer, T. (2015). Wiener's prefiguring of a cybernetic design theory. IEEE Technology and Society Magazine, 34(3), 52-59. Available at: http://www.dx.doi.org/10.1109/MTS.2015.2461172

Fischer, T., \& Richards, L. D. (in press). From goal-oriented to constraint-oriented design: The cybernetic intersection of design theory and systems theory. Leonardo Journal. Available at: http://www.dx.doi.org/10.1162/LEON_a_00862

Frayling, C. (1993). Research in art and design. Royal College of Art Research Papers, 1(1).

Frazer, J. (1993). The architectural relevance of cybernetics. Systems Research, 10(3), 43-48. Available at: http://www.dx.doi.org/10.1002/sres.3850100307

Frazer, J. (1995). An evolutionary architecture. London: Architectural Association. Retrieved from http://www.aaschool.ac.uk/publications/ea/intro.html

Furtado Cardoso Lopes, G. M. (2008). Cedric Price's Generator and the Frazers' systems research. Technoetic Arts, 6(1), 55-72. Available at: http://www.dx.doi.org/10.1386/tear.6.1.55 1

Furtado Cardoso Lopes, G. M. (2009a). Gordon Pask: exchanges between cybernetics and architecture and the envisioning of the IE. Kybernetes, 38(7/8), 1317-1331. Available at: http://www.dx.doi.org/10.1108/03684920910976998

Furtado Cardoso Lopes, G. M. (2009b). Pask's encounters: from a childhood curiosity to the envisioning of an evolving environment : exchanges between cybernetics and architecture. Vienna: Edition Echoraum.

Gage, S. (2006). The wonder of trivial machines. Systems Research and Behavioral Science, 23(6), 771-778. Available at: http://www.dx.doi.org/10.1002/sres.763

Gage, S. (2007a). Constructing the user. Systems Research and Behavioral Science, 24(3), 313-322. Available at: http://www.dx.doi.org/10.1002/sres.789

Gage, S. (2007b). How to design a black and white box. Kybernetes, 36(9/10), 1329 1339. Available at: http://www.dx.doi.org/10.1108/03684920710827337

Gedenryd, H. (1998). How designers work: Making sense of authentic cognitive activities. Lund University Cognitive Studies, 75. Retrieved from http://lup.lub.lu.se/record/18828/file/1484253.pdf

Glanville, R. (1997). A ship without a rudder. In R. Glanville \& G. de Zeeuw (Eds.), Problems of excavating cybernetics and systems. Southsea: BKS+.

Glanville, R. (1999). Researching design and designing research. Design Issues, 15(2), 80-91. Available at: http://www.dx.doi.org/10.2307/1511844 
Glanville, R. (2002). Second order cybernetics. In F. Parra-Luna (Ed.), Systems science and cybernetics. In Encyclopaedia of life support systems (EOLSS). Oxford: EoLSS. Retrieved from http://www.eolss.net/

Glanville, R. (2004a). Appropriate theory. In J. Redmond, D. Durling \& A. de Bono (Eds.), Futureground: Proceedings of the Design Research Society international conference 2004. Melbourne: Monash University.

Glanville, R. (2004b). The purpose of second-order cybernetics. Kybernetes, 33(9/10), 1379-1386. Available at: http://www.dx.doi.org/10.1108/03684920410556016

Glanville, R. (2006a). Construction and design. Constructivist Foundations, 1(3), 103110. Retrieved from http://www.univie.ac.at/constructivism/journal/1/3/103.glanville

Glanville, R. (2006b). Design and mentation: Piaget's constant objects. The Radical Designist, 0. Retrieved from http://www.iade.pt/designist/pdfs/000 05.pdf

Glanville, R. (Ed.). (2007a). Cybernetics and design. Special double issue of Kybernetes, 36(9/10). Retrieved from http://www.emeraldinsight.com/toc/k/36/9\%2F10

Glanville, R. (2007b). Designing complexity. Performance Improvement Quarterly, 20(2), 75-96. Available at: http://www.dx.doi.org/10.1111/j.19378327.2007.tb00442.x

Glanville, R. (2007c). Try again. Fail again. Fail better: The cybernetics in design and the design in cybernetics. Kybernetes, 36(9/10), 1173-1206. Available at: http://www.dx.doi.org/10.1108/03684920710827238

Glanville, R. (2009a). A (Cybernetic Musing): Design and cybernetics. Cybernetics and Human Knowing, 16(3/4), 175-186. Retrieved from http://www.chkjournal.org/administrator/components/com_webjournal/assets/co lumns/idPublication 421.pdf

Glanville, R. (2009b). A (cybernetic) musing: Certain propositions concerning prepositions. In The black boox, volume III: 39 steps (pp. 319-329). Vienna: Edition Echoraum. (Reprinted from: Cybernetics and Human Knowing, 12(3), pp. 87-95, 2005).

Glanville, R. (2009c). A (cybernetic) musing: Design and cybernetics. In The black boox, volume III: 39 steps (pp. 423-425). Vienna: Edition Echoraum. (Reprinted from: Cybernetics and Human Knowing, Vol. 16 No. 3/4, pp. 175-86, 2009).

Glanville, R. (2010). Freedom and the machine. Inaugural Lecture. University College London, London. March 10, 2010.

Glanville, R. (2011a). A (cybernetic) musing: Wicked problems. Cybernetics and Human Knowing, 19(1-2), 163-173. Retrieved from http://www.chkjournal.org/administrator/components/com_webjournal/assets/co lumns/idPublication 519.pdf

Glanville, R. (2011b). Introduction: A conference doing the cybernetics of cybernetics. Kybernetes, 40(7/8), 952-963. Available at: http://www.dx.doi.org/doi:10.1108/03684921111160197

Glanville, R. (Ed.). (2012). Trojan Horses: A rattle bag from the 'Cybernetics: Art, design, mathematic - A meta-disciplinary conversation' post-conference workshop. Vienna: Edition echoraum.

Glanville, R. (2013). Radical constructivism = second order cybernetics. Cybernetics and Human Knowing, 19(4), 27-42. Retrieved from http://www.ingentaconnect.com/content/imp/chk/2012/00000019/00000004/art0 0003

Glanville, R. (2014a). Acting to Understand and Understanding to Act. Kybernetes, 43(9/10). Available at: http://www.dx.doi.org/10.1108/K-07-2014-0147 
Glanville, R. (2014b). Why design research? In The Black Boox, volume II: Living in Cybernetic Circles (pp. 111-120). Vienna: Edition Echoraum. (Reprinted from: Jacues, R. and Powell, J. (Eds.), Design, science, method: Proceedings of the 1980 Design Research Society conference, Westbury House, Guildford, pp. 8694, 1981. ).

Glanville, R. (2015). The sometimes uncomfortable marriages of design and research. In P. A. Rogers \& J. Yee (Eds.), The routledge companion to design research (pp. 9-22). London: Routledge.

Glanville, R., Griffiths, D., \& Baron, P. (Eds.). (2014). A circularity in learning. Special double issue of Kybernetes, 43(9/10). Retrieved from http://www.emeraldinsight.com/toc/k/43/9\%2F10

Glanville, R., \& Sweeting, B. (Eds.). (2011). Cybernetics: Art, design, mathematics-A meta-disciplinary conversation: Papers from the 2010 conference of the American Society for Cybernetics. Special double issue of Kybernetes, 40(7/8). Retrieved from http://www.emeraldinsight.com/toc/k/40/7\%2F8

Goodbun, J. (2011). Gregory Bateson's ecological aesthetics: An addendum to urban political ecology. Field, 4(1), 35-46. Retrieved from http://www.fieldjournal.org/uploads/file/2011 Volume 4/field-journal_Ecology.pdf

Gooding, D. (1992). Putting agency back into experiment. In A. Pickering (Ed.), Science as practice and culture (pp. 65-112). Chicago, IL: University of Chicago Press.

Grand, S., \& Jonas, W. (2012). Mapping design research. Basel: Birkhäuser.

Herr, C. M. (2015). The Big Picture: Relating Design, Second Order Cybernetics and Radical Constructivism. Cybernetics \& Human Knowing, 22(2/3), 107-114.

Hohl, M., \& Sweeting, B. (Eds.). (2015). Composing conferences. Special issue of Constructivist Foundations, 11(1). Retrieved from http://www.univie.ac.at/constructivism/journal/11/1

Hollingsworth, R., \& Müller, K. H. (2008). Transforming socio-economics with a new epistemology. Socio-Economic Review, 6(3), 395-426. Available at: http://www.dx.doi.org/10.1093/ser/mwn006

Jonas, W. (2007a). Design research and its meaning to the methodological development of the discipline. In R. Michel (Ed.), Design research now: Essays and selected projects (pp. 187-206). Basel: Birkhäuser.

Jonas, W. (2007b). Research through DESIGN through research: A cybernetic model of designing design foundations. Kybernetes, 36(9/10), 1362-1380. Available at: http://www.dx.doi.org/10.1108/03684920710827355

Jonas, W. (2012). Exploring the swampy ground. In S. Grand \& W. Jonas (Eds.), Mapping design research (pp. 11-41). Basel: Birkhäuser.

Jonas, W. (2014). The strengths / limits of Systems Thinking denote the strengths / limits of Practice-Based Design Research. FORMakademisk, 7(4). Available at: http://www.dx.doi.org/10.7577/formakademisk.789

Jonas, W. (2015a). A cybernetic model of design research: Towards a trans-domain of knowing. In P. A. Rogers \& J. Yee (Eds.), The routledge companion to design research (pp. 23-37). London: Routledge.

Jonas, W. (2015b). Research Through Design Is More than Just a New Form of Disseminating Design Outcomes [Open peer commentary on the article "Developing a Dialogical Platform for Disseminating Research through Design" by Abigail C. Durrant, John Vines, Jayne Wallace \& Joyce Yee]. Constructivist Foundations, 11(1), 32-36. Retrieved from http://www.univie.ac.at/constructivism/journal/11/1/032.jonas 
Jones, J. C. (1984). How my thoughts about design methods have changed during the years. In Essays in design (pp. 13-27). Chichester: WIley. (Reprinted from: J Christopher Jones, Dear Architects, College of Architecture, Virginia Polytechnic Institute and State University, 1974).

Jones, P. (2014). Design Research Methods in Systemic Design. Paper presented at RSD3, Third Symposium of Relating Systems Thinking to Design, Oslo, Norway. http://systemic-design.net/rsd3-proceedings/

Knorr Cetina, K. (1992). The couch, the cathedral, and the laboratory: On the relationship between experiment and laboratory in science. In A. Pickering (Ed.), Science as practice and culture (pp. 113-138). Chicago, IL: University of Chicago Press.

Krippendorff, K. (2007). The cybernetics of design and the design of cybernetics. Kybernetes, 36(9/10), 1381-1392. Available at: http://www.dx.doi.org/10.1108/03684920710827364

Krueger, T. (2007). Design and prosthetic perception. Kybernetes, 36(9/10), 1393-1405. Available at: http://www.dx.doi.org/10.1108/03684920710827373

Lautenschlaeger, G., \& Pratschke, A. (2011). Don't give up! Media art as an endless conversational process. Kybernetes, 40(7/8), 1090-1101. Available at: http://www.dx.doi.org/10.1108/03684921111160322

Littlewood, J. (1964). A laboratory of fun. New Scientist, 22(391), 432-433.

Lobsinger, M. L. (2000). Cybernetic Theory and the Architecture of Performance: Cedric Price's Fun Palace. In S. W. Goldhagen \& R. Legault (Eds.), Anxious modernisms: Experimentatiion in post-war architectural culture (pp. 119-139). Cambirdge, MA: MIT Press.

Mathews, S. (2005). The Fun Palace: Cedric Price's experiment in architecture and technology. Technoetic Arts: A Journal of Speculative Research, 3(2), 73-91. Available at: http://www.dx.doi.org/10.1386/tear.3.2.73/1

Mathews, S. (2006). The Fun Palace as virtual architecture: Cedric Price and the practices of indeterminacy. Journal of Architectural Education, 59(3), 39-48.

Mathews, S. (2007). From Agit-Prop to Free Space: The Architecture of Cedric Price. London: Black Dog.

Mead, M. (1968). The cybernetics of cybernetics. In H. von Foerster, J. D. White, L. J. Peterson \& J. K. Russell (Eds.), Purposive Systems (pp. 1-11). New York, NY: Spartan Books.

Medawar, P. (1996). Is the scientific paper a fraud? In The strange case of the spotted mice and other classic essays on science (pp. 33-39). Oxford: Oxford University Press. (Reprinted from: The Listener, 70, 12 September 1963).

Michel, R. (2007). Design research now: Essays and selected projects. Basel: Birkhäuser.

Müller, A., \& Müller, K. H. (Eds.). (2007). An unfinished revolution? Heinz von Foerster and the Biological Computer Laboratory (BCL), 1958-1976. Vienna: Edition Echoraum.

Müller, K. H. (2008). The new science of cybernetics: The evolution of living research designs (Vol. I: Methodology). Vienna: Edition Echoraum.

Müller, K. H. (2011). The new science of cybernetics: The evolution of living research designs (Vol. II: Theory). Vienna: Edition Echoraum.

Müller, K. H., \& Müller, A. (2011). Foreword: Re-discovering and Re-inventing Heinz von Foerster. Cybernetics and Human Knowing, 18(3/4), 5-16. Retrieved from http://www.univie.ac.at/constructivism/archive/fulltexts/435.pdf 
Müller, K. H., \& Riegler, A. (2014a). A New Course of Action. Constructivist Foundations, 10(1), 1-6. Retrieved from http://www.univie.ac.at/constructivism/journal/10/1/001.editorial

Müller, K. H., \& Riegler, A. (2014b). Second-Order Science: A Vast and Largely Unexplored Science Frontier. Constructivist Foundations, 10(1), 7-15. Retrieved from http://www.univie.ac.at/constructivism/journal/10/1/007.introduction

Negroponte, N. (1975). Soft architecture machines. Cambridge, MA: MIT Press.

Nicolescu, B. (2012). Transdisciplinarity: the hidden third, between the subject and the object. Human \& Social Studies, 1(1), 13-28. Available at: http://www.dx.doi.org/10.2478/v10317-012-0002-5

Nowotny, H., Scott, P., \& Gibbons, M. (2006). Re-thinking science: Mode 2 in societal context. In E. G. Carayannis \& D. F. J. Campbell (Eds.), Knowledge creation, diffusion, and use in innovation networks and knowledge clusters. A comparative systems approach across the United States, Europe and Asia (pp. 39-51). Westport, CT: Praeger.

Obrist, H. U., \& Price, C. (2003). Re: CP: Birkhäuser Basel.

Pask, G. (1963). The conception of a shape and the evolution of a design. In J. C. Jones \& D. G. Thornley (Eds.), Conference on Design Methods, September, 1962 (pp. 153-167). Oxford: Pergamon Press. Retrieved from http://pangaro.com/pask/pask conception of shape and evolution of design.pdf

Pask, G. (1969). The architectural relevance of cybernetics. Architectural Design, 39(9), 494-496.

Pask, G. (1976). Conversation theory: Applications in education and epistemology. Amsterdam: Elsevier. Retrieved from http://pangaro.com/pask/ConversationTheory.zip

Pickering, A. (Ed.). (1992). Science as Practice and Culture. Chicago: University of Chicago Press.

Pickering, A. (1993). The Mangle of Practice: Agency and Emergence in the Sociology of Science. American Journal of Sociology, 99(3), 559-589. Available at: http://www.dx.doi.org/10.2307/2781283. Retrieved from http://www.jstor.org/stable/2781283

Pickering, A. (1995). The Mangle of Practice: Time, Agency, and Science. Chicago: University of Chicago Press.

Pickering, A. (2010). The cybernetic brain: Sketches of another future. Chicago, IL: University of Chicago Press.

Pratschke, A. (2007). Architecture as a verb: cybernetics and design processes for the social divide. Kybernetes, 36(9/10), 1458-1470. Available at: http://www.dx.doi.org/10.1108/03684920710827418

Ramsgard Thomsen, M. (2007). Drawing a live section: explorations into robotic membranes. Kybernetes, 36(9/10), 1471-1485. Available at: http://www.dx.doi.org/10.1108/03684920710827427

Rawes, P. (2007). Second-order cybernetics, architectural drawing and monadic thinking. Kybernetes, 36(9/10), 1486-1496. Available at: http://www.dx.doi.org/10.1108/03684920710827436

Rawes, P. (Ed.). (2013). Relational architectural ecologies: Architecture, nature and subjectivity. London: Routledge.

Richards, L. D. (2015). Designing Academic Conferences in the Light of Second-Order Cybernetics. Constructivist Foundations, 11(1), 65-73. Retrieved from http://www.univie.ac.at/constructivism/journal/11/1/065.richards 
Riegler, A., \& Müller, K. H. (Eds.). (2014). Second-order science. Special issue of Construcivist Foundations, 10(1). Retrieved from http://www.univie.ac.at/constructivism/journal/10/1

Rittel, H. (1972). On the planning crisis: Systems analysis of the "first and second generations". Bedriftskonomen, 8, 390-396.

Rittel, H., \& Webber, M. (1973). Dilemmas in a general theory of planning. Policy Sciences, 4, 155-169.

Rittel, H., \& Webber, M. (1984). Planning Problems are Wicked Problems. In N. Cross (Ed.), Developments in Design Methodology (pp. 135-144). Chichester: Wiley.

Rogers, P. A., \& Yee, J. (Eds.). (2015). The routledge companion to design research. London: Routledge.

Schneidewind, U., \& Augenstein, K. (2012). Analyzing a transition to a sustainabilityoriented science system in Germany. Environmental Innovation and Societal Transitions, 3, 16-28. Available at: http://www.dx.doi.org/10.1016/j.eist.2012.04.004

Schön, D. A. (1988). Designing: Rules, types and words. Design Studies, 9(3), 181-190. Available at: http://www.dx.doi.org/10.1016/0142-694X(88)90047-6

Schön, D. A. (1991). The reflective practitioner: How professionals think in action. Farnham: Arena. (Original work published: 1983).

Scott, B. (2003). "Heinz von Foerster-An appreciation" (Revisited). Cybernetics and Human Knowing, 10(3/4), 137-149.

Scott, B. (2004). Second-order cybernetics: An historical introduction. Kybernetes, 33(9/10), 1365-1378. Available at: http://www.dx.doi.org/10.1108/03684920410556007

Scott, B. (2011). Explorations in second-order cybernetics: Reflections on cybernetics, psychology and education. Vienna: Edition Echoraum.

Simon, H. A. (1996). The sciences of the artificial (3rd ed.). Cambridge, MA: MIT Press. Retrieved from http://m.friendfeedmedia.com/092e5a73c91e0838eeb11e0fe90edaf9e9afc065 (Original work published: 1969).

Snow, C. P. (1961). The Two Cultures and the Scientific Revolution. New York: Cambridge University Press.

Spiller, N. (Ed.). (2002). Cyber_reader: Critical writings for the digital era. London: Phaidon Press.

Spiller, N. (2006). Visionary architecture: Blueprints of the modern imagination. London: Thames and Hudson.

Sweeting, B. (2014). Architecture and undecidability: Explorations in there being no right answer-Some intersections between epistemology, ethics and designing architecture, understood in terms of second-order cybernetics and radical constructivism. PhD Thesis, UCL, London. Retrieved from https://iris.ucl.ac.uk/iris/publication/972511/1

Sweeting, B. (2015a). Architecture and Second Order Science. Paper presented at the 59th Annual Meeting of the International Society for the Systems Sciences, Berlin, Germany. http://journals.isss.org/index.php/proceedings59th/article/view/2688

Sweeting, B. (2015b). Conversation, Design and Ethics: The Cybernetics of Ranulph Glanville. Cybernetics \& Human Knowing, 22(2-3), 99-105. Retrieved from http://www.ingentaconnect.com/content/imp/chk/2015/00000022/F0020002/art0 0012

Sweeting, B. (2015c). Cybernetics of practice. Kybernetes, 44(8/9), 1397-1405. Available at: http://www.dx.doi.org/10.1108/K-11-2014-0239 
Sweeting, B., \& Hohl, M. (2015). Exploring Alternatives to the Traditional Conference Format: Introduction to the Special Issue on Composing Conferences. Constructivist Foundations, 11(1), 1-7. Retrieved from http://www.univie.ac.at/constructivism/journal/11/1/001.editorial

Toffler, A. (1970). Future shock: A study of mass bewilderment in the face of accelerating change. London: Bodley Head.

Umpleby, S. (2003). Heinz von Foerster and the Mansfield Amendment. Cybernetics And Human Knowing, 10(3-4), 187-190.

Umpleby, S., \& Dent, E. (1999). The Origins and Purposes of Several Traditions in Systems Theory and Cybernetics. Cybernetics and Systems: An International Journal, 30(2), 79-103. Available at: http://www.dx.doi.org/10.1080/019697299125299

Upitis, A. (2013). Alexander's Choice: How Architecture avoided Computer Aided Design c. 1962. In A. Dutta (Ed.), A Second Modernism: MIT, Architecture, and the 'Techno-Social' Moment (pp. 474-505). Cambridge, MA: SA+P Press.

van Ditmar, D. F., \& Glanville, R. (Eds.). (2013). Listening: Proceedings of ASC conference 2011. Special double issue of Cybernetics and Human Knowing, 20(1-2). Retrieved from http://www.chkjournal.org/index.php/component/webjournal/?view=issue\&cid= $\underline{232}$

von Foerster, H. (1962). Perception of form in biological and man-made systems. In E. J. Zagorski (Ed.), Transactions of the I.D.E.A. Symposion (pp. 10-37). Urbana, IL: University of Illionois.

von Foerster, H. (Ed.). (1995). Cybernetics of cybernetics: Or, the control of control and the communication of communication (2nd ed.). Minneapolis, MN: Future Systems. (Original work published: 1974).

von Foerster, H. (2003a). Cybernetics of cybernetics. In Understanding understanding: Essays on cybernetics and cognition (pp. 283-286). New York, NY: SpringerVerlag. (Reprinted from: Communication and control, pp. 5-8, by K. Krippendorff, Ed., 1979, New York, NY: Gordon and Breach).

von Foerster, H. (2003b). Understanding understanding: Essays on cybernetics and cognition. New York, NY: Springer-Verlag.

von Foerster, H., \& Poerksen, B. (2002). Understanding systems (K. Leube, Trans.). New York, NY: Kluwer Academic.

Wiener, N. (1950). The Human Use of Human Beings: Cybernetics and Society. London: Eyre and Spottiswoode. 